REVISTA ANDALUZA DE ANTROPOLOGÍA.

NÚMERO12:PATRIMONIOINMATERIAL:REDUCCIONISMOS, CONFLICTOSE INSTRUMENTALIZACIONES. INTANGIBLE CULTURAL HERITAGE: REDUCTIONISMS, CONFLICTS AND INSTUMENTALIZATIONS.

MARZO DE 2017

ISSN 2174-6796

[pp. 31-47]

http://dx.doi.org/10.12795/RAA.2017.12.02

Recibido: 17/10/2016

Aceptado: 04/01/2017

\title{
AVENTURAS Y DESVENTURAS DE UNA HERMOSA CONVENCIÓN INTERNACIONAL
}

\section{ADVENTURES AND MISADVENTURES OF A BEAUTIFUL INTERNATIONAL CONVENTION.}

\section{Cécile Duvelle}

Secretaria de la Convención de la UNESCO para la Salvaguardia del Patrimonio Cultural Inmaterial de 2008 a $2015^{1}$

\section{Traducción}

Texto original en francés traducido por Susana Irigaray Soto. Directora del Museo etnológico de Navarra.

\section{Resumen.}

Si bien nadie cuestiona seriamente los principios de una Convención internacional que pretende salvaguardar el Patrimonio Cultural Inmaterial, y eso a pesar de las dudas que presidieron su elaboración, los diez primeros años de trayectoria demuestran que la Convención no ha encontrado todavía su "zona de confort". Más allá de los objetivos

\footnotetext{
1. Las fuentes de este artículo son todas exclusivamente públicas, conforme al deber de confidencialidad de la autora como antigua funcionaria de la UNESCO que se recoge en las Normas de conducta de la administración pública internacional, punto 33: "Es deber indudable de todos los funcionarios públicos internacionales mantener las mejores relaciones posibles con los gobiernos y evitar cualquier acción que pueda obstaculizarlas. No deben interferir en las políticas ni en los asuntos de los gobiernos. Es inaceptable que, individual o colectivamente, critiquen o traten de desacreditar a un gobierno".
} 
de salvaguardia o de la posición central que ha dado a las comunidades portadoras en el proceso de identificación y de salvaguardia, quedan muchas dificultades a nivel internacional, especialmente en lo que se refiere a las inscripciones en las listas indicativas, cosa que ilustra bien cómo la propia gestión de la Convención y también los procesos de candidatura e inscripción, así como la utilización de las listas pueden, a veces, apartarse del espíritu mismo de este instrumento normativo que, sin embargo, ha abierto un horizonte nuevo, renovador, en el discurso patrimonial.

\title{
Palabras Claves
}

Patrimonio cultural inmaterial, salvaguardia, gobernanza, listas, comunidades, Estados, Comité Intergubernamental para la Salvaguardia del Patrimonio Cultural Inmaterial, Directivas Operacionales.

\begin{abstract}
While the principle of an international convention to safeguard the intangible cultural heritage is no longer seriously challenged by anyone, despite the hesitations that led to its elaboration, the first ten years of its implementation has yet to find its 'comfort' position. Beyond the safeguarding objectives and the centrality of communities of practitioners in the process of identification and safeguarding, there are still many difficulties in the implementation of the Convention. The article focuses mainly on international implementation, particularly inscriptions on the lists, illustrating how the governance of the Convention, as well as the nomination and inscription process and the use of lists sometimes run the risk of deviating from the very spirit of this normative instrument, which has opened up a new and highly innovative horizon in heritage discourse.
\end{abstract}

\section{Key words}

Intangible cultural heritage, safeguard, governance, lists, communities, States, Intergovernmental Committee for the Safeguarding of the Intangible Cultural Heritage, Operational Directives

\section{EL ESCENARIO}

La idea de salvaguardar el patrimonio cultural inmaterial mediante una Convención internacional ha sido, sin ninguna duda, una buena idea. Nadie o casi nadie lo niega a día de hoy. Con la toma de conciencia del rápido menoscabo de la diversidad cultural sobrevenido por el proceso de mundialización, la necesidad de salvaguardia urgente del patrimonio inmaterial se impuso, llegando en 2003 a la adopción de la Convención para la Salvaguaria del Patrimonio Cultural Inmaterial por parte de la Conferencia General de la UNESCO. 
Sin embargo, no ha sido fácil hacer entrar lo inmaterial en la flor y nata patrimonial, ampliando la definición de "patrimonio cultural" a las manifestaciones hasta entonces calificadas como "folklóricas", "tradicionales" o "populares". El exclusivo club de los expertos en patrimonio "tangible" ha considerado a esta criatura amorfa e inasible como un niño salvaje, molesto e indomable. Tras las reticencias y, a veces, las bromas o la indiferencia, ha hecho falta rendirse a la evidencia: el patrimonio cultural inmaterial existe de forma evidente. $Y$, a pesar de ese calificativo casi evanescente de "inmaterial", se encuentra en expresiones muy concretas en la vida humana. Su definición, que a veces se juzga como engañosa, aproximada o demasiado amplia, no puede ocultar el hecho de que ha jugado, aun hoy en día, un papel fundamental en la vida y el desarrollo de todas las sociedades humanas y que constituye la base de las culturas actuales. Por suerte, una masa crítica de especialistas, de particulares y de instituciones involucradas en el ámbito de la salvaguardia, convencidos del fundamento de esta necesidad, así como la determinación del entonces Director General de la UNESCO, Koïchiro Matsuura, supo vencer todas o casi todas las reticencias para llevar a cabo la adopción de un texto consensuado.

Hay que reconocer que los redactores de la Convención, los estados miembros de la UNESCO, fueron ambiciosos, se puede decir revolucionarios, en algunos de sus planteamientos, particularmente en la definición misma del patrimonio inmaterial. He aquí una muestra: son las comunidades, los grupos y, en algunos casos, los propios individuos quienes identifican y definen lo que consideran su patrimonio cultural. Supone una revolución en el mundo de los expertos pues se ha invertido el criterio de autoridad. El portador, el que "pone en práctica", esa persona a quien este patrimonio proporciona "un sentimiento de identidad y de continuidad", tiene esta vez la palabra, libre de toda validación científica. Su palabra, con toda su subjetividad, es la palabra válida. Para algunos, esto significa socavar el concepto. Entonces, ¿cualquier cosa podría ser patrimonio? ¿Cualquiera puede decidir que una expresión, un conocimiento, un oficio constituyen un patrimonio cultural, su patrimonio cultural sin que instancias reconocidas y universalmente legitimadas puedan validar esa afirmación?

Frente a estos interrogantes, es también legítimo preguntarse: ¿para qué sirve el patrimonio cultural? ¿qué puede ofrecernos en términos de desarrollo y enriquecimiento personal y colectivo? ¿qué hay tan fundamental en nuestra vida en sociedad para que hagamos tantos esfuerzos por protegerlo, restaurarlo, conocerlo, enseñarlo? Las claves que nos proporciona sobre lo que somos, nuestras identidades múltiples, nuestras historias entremezcladas, nuestras interacciones con el mundo constituyen, sin duda, una respuesta que justifica la importancia que se le da en todas las sociedades humanas. Las lecciones aprendidas a través de experiencias y ensayos, de conocimientos y oficios a veces centenarios que el patrimonio nos da ayudan a las generaciones actuales a no "reinventar la rueda" cuando otras generaciones han encontrado ya soluciones a los 
desafíos recurrentes a los que la Humanidad se ha enfrentado: la relación sostenible con el medio, con la propia vida y con el resto de seres humanos. El patrimonio transmitido por los grupos sociales en un contexto cultural dado nos guía y nos enseña a ser, a la vez que nos ofrece un marco de cambio, de evolución y de mejora.

En este contexto se comprende que una definición precisa, "científica", del patrimonio inmaterial importe poco. No más que sus expresiones específicas. "Lo que debe ser protegido es la diversidad misma, no el contenido histórico que cada época le ha conferido y que no podría perpetuarse más allá de la misma" (Lévi-Strauss, 1952).

Aunque la definición de patrimonio ofrecida por la Convención puede parecer imprecisa, lo que importa es su función, su reconocimiento como patrimonio cultural por una comunidad, un grupo, unos individuos, y el sentido que tiene para ellos. Más que su forma o su manifestación externa, su misma existencia y su función es lo que importa.

Y dado que la Convención tuvo cuidado de precisar que "a los efectos de la presente Convención, se tendrá en cuenta únicamente el patrimonio cultural inmaterial que sea compatible con los instrumentos internacionales de derechos humanos existentes y con los imperativos de respeto mutuo entre comunidades, grupos e individuos y de desarrollo sostenible", hay que dejar que sean dichas comunidades, grupos o, en su caso, individuos interesados quienes identifiquen lo que estiman que constituye su patrimonio. Hay que evitar salvaguardar, ni siquiera considerar a nivel internacional para una posible inscripción en las listas o para obtener una ayuda financiera, una manifestación que puede ser considerada como patrimonio cultural por una comunidad pero que supone un problema respecto a estas exigencias universales. He aquí un bonito panorama.

\section{LAS INTUICIONES PASADAS}

Es interesante volver sobre ciertos comentarios formulados por los estados miembros de la UNESCO como reacción al anteproyecto de la Convención enviado en julio de $2012^{2}$. Australia, por ejemplo, si bien se declara "claramente a favor de las iniciativas internacionales eficaces en la preservación del patrimonio cultural inmaterial", considera que la naturaleza misma del patrimonio cultural inmaterial impide un tratamiento de inventario. "Cada región tiene su cultura propia, y cada una conlleva todo un patrimonio cultural inmaterial único y precioso para un grupo humano concreto. Sería difícil, por no decir imposible, aislar ciertas prácticas culturales (en el seno de un grupo o en diversos grupos) para darles un tratamiento especial". Estos inventarios darían lugar además a "una jerarquización no deseable y a una fosilización de las prácticas culturales vivas".

2. Doc.CLT-2003/CONF.205/5. Se puede consultar también en la página de la UNESCO los informes de las reuniones intergubernamentales de expertos sobre el anteproyecto de la Convención celebradas en 2001 y 2003. 
Barbados y Sainte-Lucie insisten en el interés de salvaguardar el patrimonio cultural inmaterial en su conjunto, no solamente aquellos elementos, expresiones o manifestaciones excepcionales.

Brasil, a priori no estrictamente opuesto al principio de listas, considera que la estrategia más importante debería ser "la creación de una red de intercambio de experiencias y de mecanismos de divulgación y de asistencia técnica para mantener las políticas nacionales de patrimonio cultural inmaterial".

Canadá se manifiesta "preocupado por el uso que podría hacerse de un instrumento normativo para privilegiar el patrimonio cultural inmaterial de algunos sectores de la sociedad".

Chile está de acuerdo con el campo de aplicación de la futura Convención y estima que no debería estar limitado y que debería incluir todo el patrimonio inmaterial, "de manera que no se vea desprovisto de protección por culpa de algunas acciones políticas de los países firmantes". Considera que "el patrimonio inmaterial en peligro debe ser considerado de forma prioritaria".

Colombia, hablando acerca de la elaboración de la lista de candidaturas, recomienda "conceder a los creadores de las expresiones y a los portadores un poder mayor en materia de decisiones de orden político e institucional".

En cuanto a los Estados Unidos, recuerdan el carácter urgente de la salvaguardia de determinados aspectos del patrimonio cultural inmaterial, mientras que "otros aspectos tienen un carácter de menor urgencia, siempre teniendo en cuenta el reconocimiento, ayuda o protección que merecen". La delegación apunta a las discrepancias de opinión entre los Estados en lo que concierne al objeto de la futura Convención: ¿Se trata de socorrer o de preservar un patrimonio que está en riesgo de desaparición definitiva? ¿Se trata de identificar un patrimonio particularmente valioso y todavía vivo? ¿Se trata de proteger el patrimonio cultural inmaterial que algún día estará amenazado por toda una serie de factores de orden social, económico, político?. La delegación vuelve también a la definición del patrimonio cultural inmaterial: "Las autoridades nacionales, conjuntamente con los expertos culturales y los miembros de las comunidades implicadas deberían ser quienes participaran en primer lugar en un proceso de decisión. Por otra parte, el hecho de "nacionalizar" así un proceso de gran carga simbólica como es la elección de las expresiones representativas del patrimonio cultural inmaterial conlleva sus propias dificultades". La delegación se declara, sin embargo, "esperanzada por la importancia que se concede a la consulta y a la participación de la comunidad cultural en materia de preservación y de protección del patrimonio cultural. En eso consiste un proceso verdaderamente democrático". Y concluye: "Una vía más directa y sencilla para una organización internacional que una Convención, sería que funcionase como lugar de legitimación de las recomendaciones 
nacionales y de coordinación de la acción internacional, así como de reconocimiento y apoyo a los planes de acción y a los proyectos ligados a la salvaguardia del patrimonio cultural inmaterial".

Francia se muestra más radical: "Consideramos que no sería oportuno debatir sobre el capítulo III (listas y comités) del presente anteproyecto, ya que no es adecuado para el patrimonio inmaterial. Aquí se trata de salvaguardia, no de crear un palmarés estableciendo una lista "de valor universal excepcional". Francia concibe la futura Convención como "un instrumento de asistencia técnica y de transferencia de conocimiento experto", confiando a la UNESCO la responsabilidad de asegurar las funciones de vigilancia y previsión, así como de coordinación de los medios intelectuales y técnicos, de refuerzo de los medios de los Estados miembros y de intercambio de información, todas ellas funciones establecidas en su misión fundamental.

Japón, gran promotor de la idea de una Convención, estima sin embargo que "el texto debería ser lo más flexible posible para que cada Estado miembro tenga la oportunidad de decidir el alcance y de definir el papel de la comunidad cultural. También es importante comprender que la Convención no debería dar lugar al reconocimiento de derechos específicos para una comunidad y que ninguna debería recibir un título, ni siquiera por razones culturales".

Líbano se pregunta sobre la autoridad que definirá los elementos del patrimonio cultural y delimitará su campo. ¿Será la comunidad local, será el estado o la comunidad internacional?. El país estima "que hay que encontrar un punto de encuentro", teniendo en cuenta las especificidades y las prioridades a cada nivel: "Al estado le incumbe la cohesión nacional y la salvaguardia de la identidad común. Las instancias intergubernamentales internacionales están sobre todo involucradas en respetar los compromisos internacionales de los Estados, así como en proteger la diversidad cultural. Las comunidades portadoras del patrimonio inmaterial se alinean en torno al elemento vivo de ese patrimonio". Así concluye que "parece que la vía estatal es la que mejor podría armonizar los diferentes grupos de prioridades".

Noruega llama la atención sobre los inventarios: "El inventario del patrimonio inmaterial podría dar lugar a una no deseable competencia entre diversas formas de patrimonio cultural inmaterial"(...) "Una solución mejor para concienciar e implicar en la salvaguardia y la preservación de nuestro patrimonio cultural inmaterial consistiría en crear un catálogo de mejores prácticas en este ámbito".

Los Países Bajos recuerdan que "las comunidades que guardan y mantienen las expresiones del patrimonio cultural inmaterial deberían poder participar de cerca en las actividades previstas o recomendadas en el texto actual". "Ya que se va a tratar de acciones que abordarán las naciones firmantes del tratado, los Países Bajos esperan que se tenga en cuenta el derecho 
de los portadores y la opinión de las comunidades interesadas en los artículos que traten sobre ello. Asimismo, habría que dejar sitio a la iniciativa de las comunidades en materia de identificación, documentación, archivo y salvaguardia del patrimonio cultural inmaterial".

En cuanto al conjunto de los países africanos, para los que esta Convención reviste una importancia especial debido a la gran riqueza de su patrimonio inmaterial, opinan "que una cláusula debería especificar, bien en el preámbulo o bien como uno de los artículos del texto, que esta Convención no será utilizada, en parte o en su totalidad, con fines que menoscaben la soberanía, la unidad y las cohesión de los estados firmantes".

Estos comentarios parecen particularmente interesantes, ya que reflejan los grandes desafíos a los que la Convención hace frente hoy.

\section{PERO, ¿CUÁLES SON LOS BENEFICIOS DE LA CONVENCIÓN?}

El primer objetivo de la Convención, tal y como está enunciado en el primer apartado de su artículo primero, es la salvaguardia. Es, en efecto, en un contexto de rápida desaparición del patrimonio inmaterial que se hace necesaria una Convención, para contrarrestarla. El preámbulo de la Convención reconoce así que "el proceso de mundialización y de transformación social [...] traen consigo graves riesgos de deterioro, desaparición y destrucción del patrimonio cultural inmaterial".

La salvaguardia, como explica el artículo 2 de la Convención, se entiende como un proceso que permite asegurar la viabilidad, la transmisión y el carácter vivo del patrimonio. La documentación, el inventario, omnipresentes en la tradición etnológica, son el medio, no el objetivo. Son útiles y necesarios sólo cuando mantienen la práctica viva. Siempre y cuando sean establecidos por las propias comunidades, con sus propias miradas e interpretaciones. La salvaguardia debe ser entendida asimismo como apoyo a los portadores, respondiendo a sus necesidades y que no sea una operación quirúrgica o un ejercicio de nostalgia realizados por expertos que saben mejor que las comunidades cómo, qué y por qué proteger.

Las listas y el registro de buenas prácticas de salvaguardia se conciben también como herramientas al servicio de la misma. La Convención describe las responsabilidades de los Estados a nivel nacional (artículos 11 a 15) y, a nivel internacional, instaura dos listas y un registro de buenas prácticas de salvaguardia (artículos 16 a 18 de la Convención), además de un mecanismo de cooperación internacional (artículos 19 a 24).

La Convención precisa los objetivos de estos diferentes mecanismos. La Lista de Patrimonio Cultural Inmaterial que requiere medidas urgentes de salvaguardia pretende "adoptar las medidas oportunas de salvaguardia" (artículo 17), mientras que la Lista Representativa del Patrimonio Cultural Inmaterial de la Humanidad quiere "dar a 
conocer mejor el patrimonio cultural inmaterial, lograr que se tome mayor conciencia de su importancia y propiciar formas de diálogo que respeten la diversidad cultural" (artículo 16). Son de señalar los acalorados debates acerca de la jerarquía entre listas. ¿Hay que privilegiar la Lista de patrimonio que requiere medidas urgentes de salvaguardia o la Lista Representativa? La Convención ordena numéricamente primero la Lista Representativa (artículo 16), luego la Lista del Patrimonio Cultural Inmaterial que requiere medidas urgentes de salvaguardia (artículo 17) y el Registro de buenas prácticas (artículo 18). Sin embargo, las directrices operativas para la aplicación de la Convención, que fueron elaboradas inmediatamente después de su adopción, revirtieron intencionadamente ese orden, colocando la salvaguardia urgente antes que la Lista Representativa. Se manifiesta así el tira y afloja entre el deseo de poner en valor y la urgencia de salvaguardar.

A tenor de los hechos, es la Lista Representativa la que ha acaparado el interés. Con 336 elementos inscritos a finales de $2015^{3}$ (frente a 43 en la Lista de patrimonio que requiere medidas urgentes de salvaguardia), ha conseguido rápidamente un sitio preponderante. En torno a ella se libran batallas que, a veces, se convierten en "cuestiones de Estado"'. Con el agravante de que se produce un alejamiento importante de sus objetivos: en lugar de servir para "dar a conocer el patrimonio cultural inmaterial, lograr que se tome conciencia de su importancia y propiciar el diálogo, poniendo así de manifiesto la diversidad cultural a escala mundial y dando testimonio de la creatividad humana", tal y como define el criterio de inscripción R2, a menudo se utiliza para afirmar una "identidad nacional", insinuar una exclusividad, un origen o un carácter "excepcional".

El parecer del comité encargado de evaluar las candidaturas a la Lista Representativa en 2011, repetido, más o menos en los mismos términos cada año, se expresa de esta manera: "El órgano subsidiario ha percibido la utilización de un vocabulario inadecuado, como son las referencias a una lista indicativa, a la Lista del patrimonio mundial o al patrimonio mundial de la Humanidad, a las obras maestras y otras por el estilo, lo que podría entenderse como una falta de comprensión, por parte de los Estados remitentes, del carácter específico de la Convención de 2003. También se encuentran menciones recurrentes a la singularidad o a la rareza de los elementos especificos, a su carácter excepcional o valioso, su alto valor artístico, referencias a los orígenes y a la autenticidad etc. Y entre las medidas de salvaguardia, este órgano ha visto el esfuerzo dedicado a delimitar la forma pura y canónica de un elemento, o a restablecer sus características "originales". [...] Exhortar a los Estados a tomar en consideración la importancia de respetar el espíritu y la letra de

3. Incluso restando los 90 elementos declarados Obras maestras del patrimonio oral e inmaterial de la Humanidad antes de la entrada en vigor de la Convención, incluidos automáticamente en 2009, hay otros 246 bienes inscritos en esta lista, más de seis veces la Lista de medidas urgentes de salvaguardia.

4. Consultar las actas del Comité intergubernamental desde 2009. 
la Convención, que no pretende promover la competencia entre elementos o encerrar el patrimonio cultural inmaterial dentro de un patrón fijo e idealizado"s.

Estos comentarios no logran invertir esta tendencia, que permanece e incluso se acentúa año tras año. Tampoco lo consiguen los esfuerzos de la Secretaría de la UNESCO, que no deja pasar la ocasión, especialmente durante las numerosas acciones de fomento en los diferentes países, de recordar cuáles son los objetivos de la salvaguardia y las numerosas situaciones de riesgo.

Otro tema que surge en las candidaturas es la cuestión de la comercialización. Nuevamente, el órgano que evalúa las candidaturas se expresa: "El órgano subsidiario ha vuelto a abordar la cuestión de la comercialización de los elementos, reiterando su postura inicial de que "el aspecto comercial no está a priori descartado, dado el papel que juega el patrimonio cultural inmaterial como factor de desarrollo económico" (Documento ITH/09/4.COM/ CONF.209/ INF.6). [...] "la práctica y la transmisión de algunos elementos, especialmente en el caso de aquellos relacionados con la artesanía, están estrechamente ligadas a la generación de recursos. El órgano subsidiario ha señalado la importancia de la implicación de las comunidades en el proceso de elaboración de las medidas de salvaguardia con el fin de asegurar que las comunidades afectadas se beneficien de la inscripción y de la repercusión que lleva aparejada, más que los Estados o las empresas privadas. El órgano subsidiario considera igualmente que las medidas de salvaguardia deberían tener en cuenta los perjuicios que una comercialización descontrolada pueden conllevar para las funciones sociales y culturales, así como para la viabilidad del patrimonio cultural inmaterial. A este respecto, anima a los Estados miembros a respetar el espíritu de los párrafos 116 y 117 de las directrices operativas, que reconocen la importancia de las actividades comerciales - en especial aquellas que se ocupan de la promoción y de la sensibilización- siempre recordando que es esencial que sean las comunidades interesadas quienes controlen esas actividades".

El comité se ve también obligado a recordar los principios fundamentales: "A lo largo de sus revisiones, el órgano subsidiario ha vuelto una y otra vez al tema fundamental de las comunidades. Las comunidades son el centro de cada uno de los cinco criterios, por supuesto en la definición del bien patrimonial en el criterio R.1, porque sólo las comunidades interesadas pueden reconocer una u otra práctica, representación, expresión, conocimiento $u$ oficio como constitutivos de su patrimonio inmaterial. Y, a su vez, ese patrimonio les proporciona un sentimiento de identidad y de continuidad. Pero también las comunidades son centrales en el resto de criterios. El diálogo que tiene en cuenta la diversidad cultural deber ser estimulado y propiciado por ellas, así como a través de los contactos entre ellas;

5. Disponible en http://www.unesco.org/culture/ich/doc/src/ITH-11-6.COM-CONF.20613+Corr.+Add.-FR.pdf

6. Disponible en http://www.unesco.org/culture/ich/doc/src/ITH-11-6.COM-CONF.206$13+$ Corr.+Add.-FR.pdf 
el significado del patrimonio cultural inmaterial es, ante todo, el que tenga para su propia comunidad, aunque no de forma exclusiva. Para el criterio R.3, el órgano subsidiario ha buscado la participación de las comunidades en las medidas de salvaguardia, no solamente por ser el objetivo o las beneficiarias de esas medidas, sino también en cuanto a su papel en su investigación y ejecución. También ha buscado la implicación de las comunidades en esas medidas, aspecto este fundamental para el éxito de cualquier esfuerzo de salvaguardia. En lo que se refiere al criterio R.4, el órgano subsidiario ha pedido demostrar que la comunidad afectada haya participado amplia y activamente en la elaboración de la candidatura en cada una de sus etapas, desde el inicio hasta el final. También exige pruebas de que la comunidad consiente en presentar la candidatura, con pleno conocimiento de causa y con la libertad de rechazar su aceptación. Se ha procurado de igual manera tener la demostración de que quienes han preparado la candidatura hayan respetado escrupulosamente todas las restricciones habituales sobre el acceso a la información del elemento propuesto. El órgano subsidiario no deja de lado las dificultades de identificar correctamente y definir la comunidad afectada por un elemento concreto. Hay que decir que el término "comunidad" no está definido en el texto de la Convención y que la noción de comunidad puede ser distinta de unas regiones a otras o en el marco de diferentes contextos políticos y culturales. A pesar de esto, el órgano subsidiario subraya la importancia de identificar claramente a la comunidad. Asimismo, remarca que la comunidad interesada tiene que estar presente desde el inicio hasta el final de la candidatura. Para los miembros del órgano subsidiario ha sido frustrante constatar que la comunidad de referencia cambiaba de una página a otra. Y si las comunidades son difíciles de definir, más difícil aún es determinar quién las representa. El órgano subsidiario ha procurado evaluar cada candidatura en sus justos términos y comprender cómo cada Estado peticionario y cada comunidad habían tratado la cuestión de saber quién, desde el seno de la comunidad, podía ejercer su representación y hablar en su nombre. Para esto no basta una norma o reglamento, ya que hay tantas formas de representatividad como comunidades, pero el órgano subsidiario ha buscado siempre fundamentar sus decisiones y conclusiones en "un criterio sensible y flexible respecto a esta cuestión"7.

El servicio de supervisión interna de la UNESCO, en su evaluación de la Convención de octubre de $2013^{8}$, recomienda frente a este problema "aclarar todas las ideas erróneas relativas al objetivo y uso de la Lista Representativa que tienen los Estados miembros y otras partes implicadas" (Recomendación 9) y "velar para que la inscripción de bienes en la Lista Representativa refleje mejor los criterios y procedimientos estipulados en el capitulo

7. Disponible en http://www.unesco.org/culture/ich/doc/src/ITH-11-6.COM-CONF.20613+Corr.+Add.-FR.pdf

8. Informe de evaluación de la Convención para la salvaguardia del Patrimonio Cultural IOS/ EVS/PI/129 REV (octubre 2013) 
12 de las directrices operativas de la Convención" (Recomendación 10).

El Comité, que en general aceptó bien las diversas recomendaciones de dicha evaluación, no secundó la propuesta de la Secretaría ${ }^{9}$ en el anteproyecto referido a estas dos recomendaciones, según el cual el Comité haría un llamamiento "a los Estados miembros y a la Asamblea general, así como a la Secretaría, a los centros de categoría 2, a las organizaciones no gubernamentales y a todo el resto de partes interesadas para [...] corregir todas las ideas erróneas sobre el objetivo y la utilización de la Lista Representativa (Recomendación 9)" y para decidirse "a asegurarse de que la inscripción de bienes en la Lista refleja de una manera más precisa los criterios y procedimientos indicados en el capitulo I.2 de las directrices operativas de la Convención" (Recomendación 10). El Comité enmendó esta propuesta, que se reformuló en el sentido de "respetar y promover los fines y la mejor utilización de la Lista Representativa" y "asegurarse de que la inscripción de los bienes en todas las Listas refleje de manera precisa los criterios y procedimientos indicados en el capítulo I de las directrices operativas de la Convención"10. El Comité evitó así poner el dedo en la llaga de la Lista Representativa, como sí hizo el Servicio de evaluación, aunque sea esta la que constituye la problemática esencial.

\section{UN SISTEMA DE GESTIÓN PARADÓJICO}

Si se examinan los diversos aspectos de la gestión, es evidente una cierta paradoja. Mientras que la Convención pone a las comunidades, grupos e individuos portadores y protagonistas del patrimonio inmaterial en el centro de todos sus procesos, los Estados acaparan la gestión.

Efectivamente, sólo los Estados pueden ratificar la Convención, cuando esta engendra derechos y deberes tanto a nivel nacional como internacional. Los informes periódicos que deben remitir a la UNESCO para dar cuenta de su aplicación les obligan a afrontar su responsabilidad. Aunque la cuestión de la contribución de la sociedad civil a estos informes fue debatida en su momento, teniendo en cuenta el papel activo que esta juega en la salvaguardia, las conclusiones fueron que "se anima al Estado a implicar a las organizaciones no gubernamentales en la preparación del informe y a incluir sus contribuciones y datos suministrados en la sección pertinente" ${ }^{11}$. Se minimiza así al máximo cualquier riesgo de discrepancia con el Estado. Un estímulo no es una obligación, y pocos países a día de hoy han integrado de manera efectiva los comentarios de las organizaciones de la sociedad civil, con la notable excepción de Suiza, que ha enviado el informe realizado por la sociedad civil como anexo a su propio informe.

\footnotetext{
9. Ver Documento ITH/13/8.COM/5.c, proyecto 8.COM.5.c.1. artículos 5.b et 8.b

10. Ver http://www.unesco.org/culture/ich/fr/D\%C3\%A9cisions/8.COM/5.c.1

11. Ver http://www.unesco.org/culture/ich/doc/src/ICH-10-2017-FR.doc
} 
Los Estados se encargan también de la acción internacional. Los Estados firmantes de la Convención deciden en asamblea general las directrices operativas para la aplicación de la Convención, detallando la manera en que pueden dar cumplimiento a sus obligaciones a nivel nacional, pero también cómo debe funcionar ese sistema a nivel internacional: criterios de inscripción o de obtención de ayuda financiera, calendario y modalidades de evaluación. Los Estados deciden las reglas del juego.

También los Estados son los únicos que pueden remitir expedientes de candidatura o peticiones de ayuda económica. El Comité Intergubernamental, compuesto por Estados miembro elegidos en la Asamblea General, decide sobre las inscripciones o la asignación de ayudas. Expertos "representantes de los Estados partes", propuestos y elegidos por dichos Estados, además de las organizaciones no gubernamentales acreditadas por los Estados y seleccionadas por ellos, analizan los expedientes de candidaturas en el Órgano de evaluación ${ }^{12}$. Este órgano, que ha evolucionado positivamente a lo largo del tiempo, ya que al comienzo sólo estaba compuesto por miembros del Comité, se ha transformado en una unidad que se ocupa de todas las listas, de las buenas prácticas de salvaguardia y de la asistencia internacional. Pero este nuevo órgano garantiza sólo a los Estados el derecho a designar quiénes pueden entrar en él. En este punto todo está bajo control también.

Esta disfunción ya fue detectada por el Servicio de supervisión interna antes mencionado en 2013, cuando afirma que: "El hecho de que los miembros del Órgano subsidiario representen a los Estados partes produce un fuerte descontento e inquietud por los posibles conflictos de intereses". Este análisis ha sido objeto de vivas tensiones en el seno del Comité. Algunos miembros han defendido con fuerza los principios de neutralidad e independencia, y quisieran que el órgano de evaluación estuviera compuesto por expertos independientes manteniendo, como prevé la Convención, que la última palabra la tengan los Estados a través del Comité. Otros desearían, por el contrario, mantener la representación gubernamental. La delegación de España, por ejemplo, refiriéndose a la supresión del Órgano subsidiario [compuesto por los Estados miembros del Comité] y su sustitución por un órgano compuesto por expertos y de ONG independientes, apuntó que la Secretaría parecía querer hacer hincapié en esta postura, añadiendo que "no estamos de acuerdo con esa recomendación puesto que el Órgano subsidiario no lleva más que cuatro años operativo. Por otra parte, todos los informes avalan el hecho de que el Órgano subsidiario funciona a la perfección; se trata de una medida demasiado drástica para ser adoptada tan pronto". Al igual que Brasil, China y Marruecos, la delegación española desearía "que se dedique más tiempo a un examen profundo de esta cuestión". En la misma línea, la delegación de Perú se declaró favorable a algunas de las recomendaciones

12. Ver el punto 27 de las directrices operativas para la puesta en práctica de la Convención. 
propuestas, pero en desacuerdo con muchos aspectos. Por ejemplo, no consideraba oportuno poner en duda las competencias de un Estado, ni su transparencia o su manera de poner en práctica la Convención. Además, no era favorable a suprimir el Órgano subsidiario $^{13}$. Tras intensos y, a veces, encontrados debates, se forjó el consenso en torno a un órgano único, el órgano de evaluación, que sigue estando compuesto en un 50\% por representantes de los Estados partes.

El Comité Intergubernamental tiene la última palabra respecto a las inscripciones. De ahí el interés en formar parte de él. Y aunque la Convención establezca (artículo 6, apartado 7) que "los Estados miembros del Comité designarán, para que los representen en él, a personas cualificadas en los diversos ámbitos del patrimonio inmaterial", las listas de participantes en el Comité presentan un gran número de responsables de asuntos exteriores, incluso aunque las delegaciones sean mixtas e incluyan expertos. No son estos últimos los que se expresan mayoritariamente y raramente son los jefes de la delegación.

\section{5. ¿UNA HUIDA HACIA ADELANTE?}

Hay cosas que producen cierta perplejidad. Cuando se asiste a los trabajos del Comitée ${ }^{14}$, no se puede por menos que constatar la falta de interés manifestada por la mayoría de los miembros respecto a los informes periódicos, que constituyen sin embargo la herramienta más pertinente y en perfecta sintonía con las funciones del Comité, que son "promover los objetivos de la Convención y fomentar y seguir su aplicación" (artículo 7(a) de la Convención). Y, por el contrario, se asiste al nerviosismo extremo que precede al momento de la inscripción en la Lista Representativa.

También se asiste a operaciones a medida en la sala durante las inscripciones. El punto de vista técnico, sustentado en la aplicación de los criterios de inscripción elaborados y aprobados por los propios Estados, son para algunos un obstáculo burocrático. Cuando la falta de información es patente, por ejemplo la ausencia de pruebas de que el elemento propuesto esté inscrito en un inventario de patrimonio inmaterial (criterio 5), o incluso la falta de pruebas concretas del libre consentimiento, previo e informado de las comunidades (criterio 4), algunos miembros del Comité se inclinan por aceptar una simple declaración del Estado peticionario, o documentos que se presentan en la propia sesión. Los debates pueden resultar tensos en estos casos.

Paralelamente, se asiste a una auténtica infrautilización, cuando no directamente a una falta de utilización, de los recursos del Fondo del patrimonio cultural inmaterial, disponible para quienes necesitan asistencia para proyectos de salvaguardia.

13. Acta de la $8^{a}$ sesión del Comité (Baku, 2013), ITH/14/9.COM/4 Rev.

14. Todas las sesiones están transmitidas por vídeo y consultables en la página web de UNESCO). 
El Comité escoge a menudo en este contexto una estrategia que parece una huida hacia adelante, lo que Marc Jacobs (2016) describe como "hop, freeze and skip". Solicita a la Secretaría que ponga a disposición delos Estados partes documentos queles permitan tener presentes todas las decisiones anteriores y ayudarles en la elaboración de candidaturas ${ }^{15}$; que les sugieran una reflexión sobre los códigos éticos ${ }^{16}$; que les recuerden los principios generales que deben presidir las inscripciones "Es importante seguir reflexionando sobre la amplitud y el alcance adecuados de un elemento y animar a los Estados peticionarios a proporcionar explicaciones claras para demostrar que los elementos propuestos corresponden a la definición del patrimonio cultural inmaterial" (19) ${ }^{17}$; que alerten sobre el lugar central que deben tener las comunidades: "Reafirmar que las comunidades, los grupos y, en su caso, los individuos portadores del patrimonio cultural inmaterial son los actores esenciales en todas las etapas de identificación, inventario, preparación, elaboración y envío de las candidaturas en el fomento de la visibilidad del patrimonio cultural inmaterial, la toma de conciencia de su importancia y la aplicación de las medidas de salvaguardia"18, e "invitar a los Estados peticionarios a que demuestren su participación en el proceso de nominación, aportando pruebas abundantes y convincentes"19 "Recordar a los Estados partes que el consentimiento libre, previo e informado significa, ante todo, el consentimiento a presentar la candidatura tal y como está redactada en el formulario, más que un apoyo al elemento en sí mismo, a sus méritos y/o a su reconocimiento por la comunidad internacional"20.

Se hace hincapié en que las inscripciones en la Lista Representativa deben respetar los objetivos de dicha lista: "Subrayar que el criterio R.2 exige que la candidatura demuestre cómo la posible inscripción contribuirá a garantizar la visibilidad y la concienciación de la importancia del patrimonio cultural inmaterial en general, no solamente del elemento inscrito" 21 " Decidir que el criterio R.2 no se considerará cumplido satisfactoriamente más que si la candidatura describe de qué manera la posible inscripción contribuirá a garantizar la visibilidad y la toma de conciencia de la importancia del patrimonio cultural inmaterial en general, no solamente del elemento inscrito en calidad de tal, y a fomentar el diálogo en el respeto a la diversidad cultural"22.

Se alerta contra los excesos ligados a la excesiva comercialización: "Recordar la importancia

15. Ver punto 19 en http://www.unesco.org/culture/ich/en/Decisions/8.COM/8

16. Ver punto 11 en http://www.unesco.org/culture/ich/fr/decisions/7.COM/6?dec=decisions\&ref_ decision=7.COM

17. Ver punto $12 \mathrm{en} \mathrm{http://www.unesco.org/culture/ich/en/Decisions/8.COM/8}$

18. Ver punto 6 en http://www.unesco.org/culture/ich/fr/decisions/7.COM/11?dec=decisions\&ref_ decision=7.COM

19. Ver punto $15 \mathrm{en} \mathrm{http://www.unesco.org/culture/ich/en/Decisions/8.COM/8}$

20. Ver punto 13 en http://www.unesco.org/culture/ich/fr/D\%C3\%A9cisions/10.COM/10

21. Ver punto 14 en http://www.unesco.org/culture/ich/fr/D\%C3\%A9cisions/7.COM/11

22. Ver punto $13 \mathrm{en} \mathrm{http://www.unesco.org/culture/ich/en/Decisions/8.COM/8}$ 
de la aplicación de los párrafos 117 y 149 de las Directrices operativas en lo que se refiere a la protección y a la utilización del emblema de la Convención e invitar a los Estados partes a tomar las medidas necesarias para evitar la deriva comercial de los elementos inscritos, en especial de los elementos genéricos que afectan a varios ámbitos, mediante la utilización del emblema de la Convención con fines de instrumentación o labelización mercantil" ${ }^{\prime 3}$ y "Subrayar que son las comunidades, los grupos y, en su caso, los individuos quienes deberían ser los principales beneficiarios de la inscripción de un elemento en la Lista Representativa, del incremento de su visibilidad y del retorno que pueda derivarse de ello"24. Pero hay dificultades a la hora de aplicar las decisiones propias cuando llega el momento de las inscripciones. Algunos miembros del Comité llegan incluso a afirmar, respondiendo así a los que recuerdan la necesidad de respetar las reglas y procedimientos establecidos en la Directrices operativas que "el Comité tiene la potestad de elegir si aplica o no los procedimientos" (Jacobs, 2016: 86).

Se pide a la Secretaría, "en aras de la coherencia, hacer una evaluación de la puesta en práctica de las anteriores decisiones del Comité en relación con la inscripción de elementos en la Lista Representativa del Patrimonio Cultural Inmaterial de la Humanidad y de la Lista de Patrimonio Cultural Inmaterial que requiere medidas urgentes de salvaguardia, la selección de propuestas para el Registro de buenas prácticas de salvaguardia y de la concesión de asistencia internacional". El informe emitido por la Secretaría, que analiza el modo en que el Comité ha aplicado sus propias decisiones en las sucesivas sesiones ${ }^{25}$, y cuyas conclusiones se dejan a expensas del Comité, se valoró positivamente pero el órgano se limitó a "tomar nota"26.

\section{6. ¿CUÁLES SON LAS PERSPECTIVAS?}

Algunos puede que sean pesimistas acerca de la evolución de esta bonita idea que es la Convención. Otros, como la autora de estas líneas, no lo somos ya que es palpable sobre el terreno, a la vista de las opiniones intercambiadas con los agentes que están en primera línea de la salvaguardia, hasta qué punto esta Convención ha abierto las puertas, ha aportado un soplo de aire fresco a estos trabajadores en la sombra. Los principios deontológicos recientemente adoptados a instancias del Comité ${ }^{27}$ no podrán ciertamente evitar algunas contradicciones y extrañas derivas en aras de la salvaguardia. Sería ingenuo también esperar milagros del nuevo capítulo de las Directrices operativas relativo a la salvaguardia del patrimonio cultural inmaterial y el desarrollo sostenible, adoptado en

23. Ver punto 6 en http://www.unesco.org/culture/ich/fr/D\%C3\%A9cisions/5.COM/6

24. Ver punto $15 \mathrm{en} \mathrm{http://www.unesco.org/culture/ich/fr/D \% C3 \% A9cisions/6.COM/13}$

25. Ver en http://www.unesco.org/culture/ich/doc/src/ITH-14-9.COM-13.d-FR.doc

26. Ver en http://www.unesco.org/culture/ich/fr/D\%C3\%A9cisions/9.COM/13.d

27. Ver en http://www.unesco.org/culture/ich/fr/ethique-et-pci-00866 
junio de $2016{ }^{28}$. El punto 176, que estipula que "los Estados partes procurarán velar por que las inscripciones del patrimonio cultural inmaterial en las listas de la Convención conforme a los artículos 16 y 17 y la selección de las mejores prácticas de salvaguardia conforme al artículo 18 no sean utilizadas de manera inadecuada o en detrimento del patrimonio cultural inmaterial y de las comunidades, los grupos o los individuos interesados, especialmente buscando ganancias económicas a corto plazo", no va sin duda a cambiar las prácticas disfuncionales a las que estamos asistiendo. Una sociedad civil cada vez más sólida está surgiendo en torno a la salvaguardia del patrimonio inmaterial, desarrollando la investigación y aportando los recursos. Ahora bien, la salvaguardia del patrimonio cultural inmaterial se realiza esencialmente a nivel local, en el seno mismo de las comunidades. No precisa necesariamente de la intervención estatal, si bien esta puede ser determinante a través de la aplicación de políticas públicas favorables. Hay Estados, incluidos algunos que no han ratificado la Convención, que ponen en práctica sólidos marcos legislativos e institucionales para impulsar y sostener esta salvaguardia. En este campo hay iniciativas ilusionantes.

La Convención ha abierto un camino de alguna manera irreversible y ha despejado un horizonte que estaba cerrado no hace tantos años. Es hacia ese horizonte al que hay que dirigir la mirada, una mirada que puede y debe ser optimista.

28. Ver http://www.unesco.org/culture/ich/es/directrices 


\section{BIBLIOGRAFÍA}

Jacobs, Marc (2016). "The Spirit of the Convention - Interlocking Principles and Ethics for Safeguarding Intangible Cultural Heritage". International Journal of Intangible Cultural Heritage, 11: 71-87.

Lévi-Strauss, Claude (1952) Race et Histoire. Paris: UNESCO. 